REVISTA ANDALUZA DE ANTROPOLOGÍA.

NÚMERO 8: TURISMO DE BASE LOCAL EN LA GLOBALIZACIÓN

MARZO DE 2015

ISSN 2174-6796

[pp. 113-140]

http://dx.doi.org/10.12795/RAA.2015.i08.06

Fecha de Recepción: 27-01-2015

Fecha de Aceptación: 14-02-2015

\title{
LOS MISTERIOS DEL PATRIMONIO Y EL TURISMO EN ELCHE. LO GLOBAL (UNESCO) EN LO LOCAL (IDENTIDAD)
}

Daniel Carmona Zubiri

Raúl Travé Molero

Antonio Miguel Nogués Pedregal

Grupo Culturdes - Universitas Miguel Hernández

\section{Resumen.}

Elche es un municipio con tres elementos patrimoniales reconocidos por la UNESCO en distintas categorías -Palmeral de Elche (2000), Misterid'Elx (2001) y Museo Escolar de Pusol (2009)- y, también, es un municipio inmerso desde hace dos décadas en un proceso de desindustrialización del sector del calzado, motor tradicional de la economía local. Para enfrentar esta situación socioeconómica, el gobierno municipal optó por un desarrollo 'sostenible' del sector turístico como vehículo para frenar el deterioro del tejido industrial y empresarial. Tras la patrimonialización de dos de sus más relevantes señas de identidad (Palmeral y Misteri) se ha incluido la Dama de Elche para conformar una "tríada identitaria" que está sirviendo de base para una estrategia de marca-ciudad que convierte el turismo en uno de los ejes del desarrollo del municipio. Frente a esta "puesta en valor" (hacia fuera), el Museo de Pusol lleva cuarenta años "dando valor" (hacia dentro) a la cultura tradicional como elemento estructural de la sociedad del Camp d'Elx $\mathrm{y}$, pese al reconocimiento UNESCO, no es contemplado como recurso en el paquete turístico diseñado hacia fuera y desde las instituciones. En este artículo se describen las prácticas diseñadas desde arribaa plicando el modelo de la mediación significativa 
del espacio turístico, y cómo este proceso influye -no sin reticencias ni conflictos- en la producción de un nuevo marco de sentido para la identidad ilicitana.

\title{
Palabras clave.
}

UNESCO, turismo cultural, patrimonialización, identidad, marca-ciudad, desarrollo sostenible.

\begin{abstract}
.
Elche is a Spanish municipality by the Mediterranean coast with three cultural elements inscribed in three different lists of UNESCO categories: Elche's Palm Grove (2000), Misteri d'Elx (2001) and Museo Escolar de Pusol (2009). For the last two decades Elche has faced a profound process of deindustrialisation of the shoe-making industry, traditional motor of the local economy. To deal with thissocio-economic situation, the local government chose the tourism sector as sustainable development and the way to relieve the decline of the industrial and entrepreneurial fabric. After the patrimonialization of two of its most important hall marks (Palm Grove and Misteri) the Lady of Elche has been included to form an "identity triad", which is been used as the basis for acity-brand strategy that makes tourism one of the axes of development of the municipality. In contrast to this strategy of promoting the heritage toward the outside, during the last forty years the Museum of Pusol has enhanced toward the inside the traditional culture as a structural element of the society of the Camp d'Elx. Despite the recognition of UNESCO, this Museum is not considered as a resource in the package designed for attracting visitors. This paper applies the model of the meaningful mediation of tourist space to analyse the practices carried out by the municipality. Furthermore the article describe show this process influencesnot with out reluctance or conflict-the production of a new framework for cultural identity among local residents.
\end{abstract}

\section{Keywords.}

UNESCO, cultural tourism, patrimonialization, identity, city-branding, sustainable development. 


\section{INTRODUCCIÓN}

Tres cosas acuden al interés del turista cuando se acerca a Elche:

su palmeral, su Misteri, y su Dama.

Joan Fuster, El País Valenciano (1962: 470)

Puede que Elche sea el único municipio del mundo con tres elementos inscritos en tres de las principales categorías patrimoniales de la UNESCO: el Palmeral de Elche, declarado Patrimonio de la Humanidad en 2000, el Misteri d'Elx reconocido como Obra Maestra del Patrimonio Oral e Inmaterial de la Humanidad en 2001, y el Centro de Cultura Tradicional Museo Escolar de Pusol inscrito en el Registro de Buenas Prácticas de Salvaguardia del Patrimonio Cultural Inmaterial en 2009. Junto a la globalidad de estos reconocimientos existe, además, un cuarto elemento custodiado en el Museo Arqueológico en Madrid, que es considerada desde su descubrimiento en 1897 como el principal depositario de la identidad ilicitana. Nos referimos, claro está, al busto íbero de la Dama de Elche.

Sin embargo, y esta es la pregunta que ha motivado este artículo, no todos estos elementos son tratados -por los agentes políticos y económicos- ni pensados o sentidos por los ilicitanos de la misma manera. Solo el Palmeral, el Misteri, y la Dama componen esa trÍada que, a través de la mediación de un espacio turístico promovido a finales de la década de los noventa por el PSOE -y tras las elección municipales de mayo de 2011- por el PP, se ha implantado desde arriba sobre el territorio y sus gentes mediante la hegemonía de un discurso de desarrollo que presenta al turismo como alternativa a la desindustrialización del municipio. Nuestra etnografía, en la que también se incluye el análisis del discurso oficializado por los principales grupos de interés políticos, empresariales y las élites sociales del territorio, evidencia las razones por las que, de momento, solo estos tres elementos, junto a la reivindicación de las imprescindibles playas que necesita cualquier destino turístico de interior que busque amparo bajo la marca 'Costa Blanca' o el consabido centro de congresos (2003) que necesita cualquier ciudad que promueva el turismo urbano, se han transformado en los principales recursos turísticos del municipio (fotografía 1). En este texto mantenemos que la selección de estos elementos desempeña hoy, sin embargo, un papel relevante en la conformación sociopolítica del Elche actual y, sobre todo, en la producción de una identidad ilicitana. 


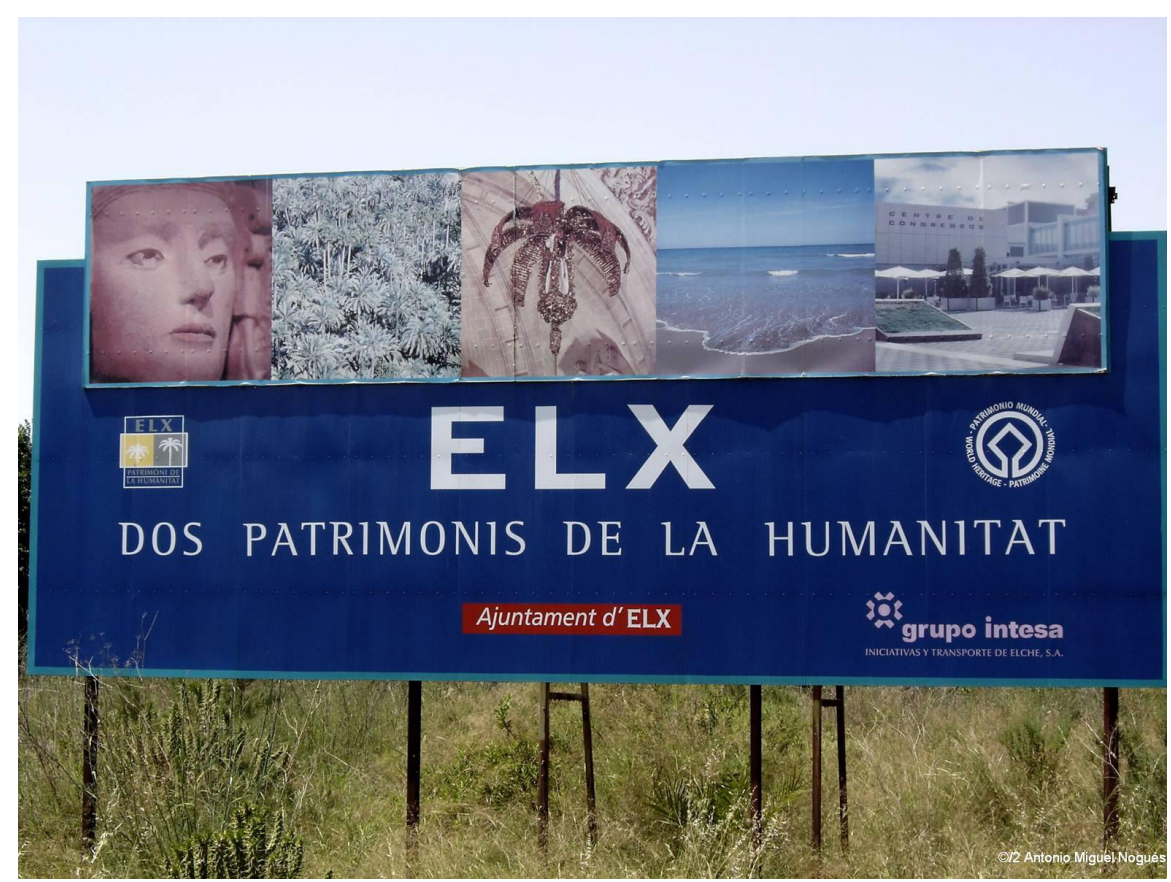

Ilustración 1: El paquete turístico de Elche (Elx en valenciano):

La Dama, el Palmeral, el Misteri, las playas y el Centro de Congresos (Elche 2006).

Esta distintiva combinación de elementos patrimoniales, que bien podría considerarse un ejemplo paradigmático para su comparación con procesos similares, se enmarca en todo un proceso ininterrumpido de acciones políticas concretas, muy marcadas por el partido político que las llevó a cabo y muy publicitadas como son, entre otras, numerosos estudios e informes sobre las potencialidades turísticas de Elche, la creación del Institut Municipal de Turisme d'Elx (2004), la campaña turística "Elche me encanta" (febrero 2008), la transformación por el PP en enero de 2012 del instituto "socialista" Turisme d'elx en VisitElche -un organismo autónomo local para la gestión del Destinola presentación en abril del Plan de Marketing VisitElche (2012) que publicitó una nueva identidad turística en torno al Palmeral, lanzó la campaña Elche, Oasis del Mediterráneo, e incorporó el Destino Elche a las nuevas tecnologías con el proyecto de blog VisitElche.com y a las redes sociales con la etiqueta \#VisitElche y sus variantes posteriores \#OasisdelMediterraneo, \#PalmeraldeEuropa, etcétera. Paralelamente, la sintonía política con el Gobierno Central y de la Generalitat favoreció la ubicación de una sede de la Escuela de Organización Industrial en Elche (junio 2012) para promover cursos de formación y emprendimiento turístico, o la redenominación del Aeropuerto de Alicante-Elche (julio 2013) ${ }^{1}$. Además, las celebraciones del Día Mundial del Turismo con presencia de autoridades internacionales, entrega de premios y reconocimientos a ilicitanos en distintas categorías; la creación (julio, 2010) de la ruta outlet en la que participan empresas locales de renombre internacional, la ordenanza municipal para

1. Orden FOM/1316/2013, de 19 de junio 
distinguir horarios de verano e invierno en el sector de la hostelería (BOP, 2013: 18) e introducir nuevos ritmos a lo cotidiano, las campañas dirigidas a la población local como "Sé turista en tu ciudad" (febrero 2011) invitando a los ilicitanos a conocer la oferta turística de su propia ciudad para que sugiriesen a familiares y amigos la visita a la ciudad o pudieran servir de guías a los visitantes, o la más reciente campaña "Nosotros somos turismo, tú también" que desde autobuses y marquesinas, invita a ejercer de buenos anfitriones con los turistas... Todo un conjunto de estrategias que producen ese espacio turístico que poco a poco transforma esa sensación de invasión que tienen algunos grupos sociales, de que el turismo no va con la ciudad de Elche, en una actitud cada vez más minoritaria.

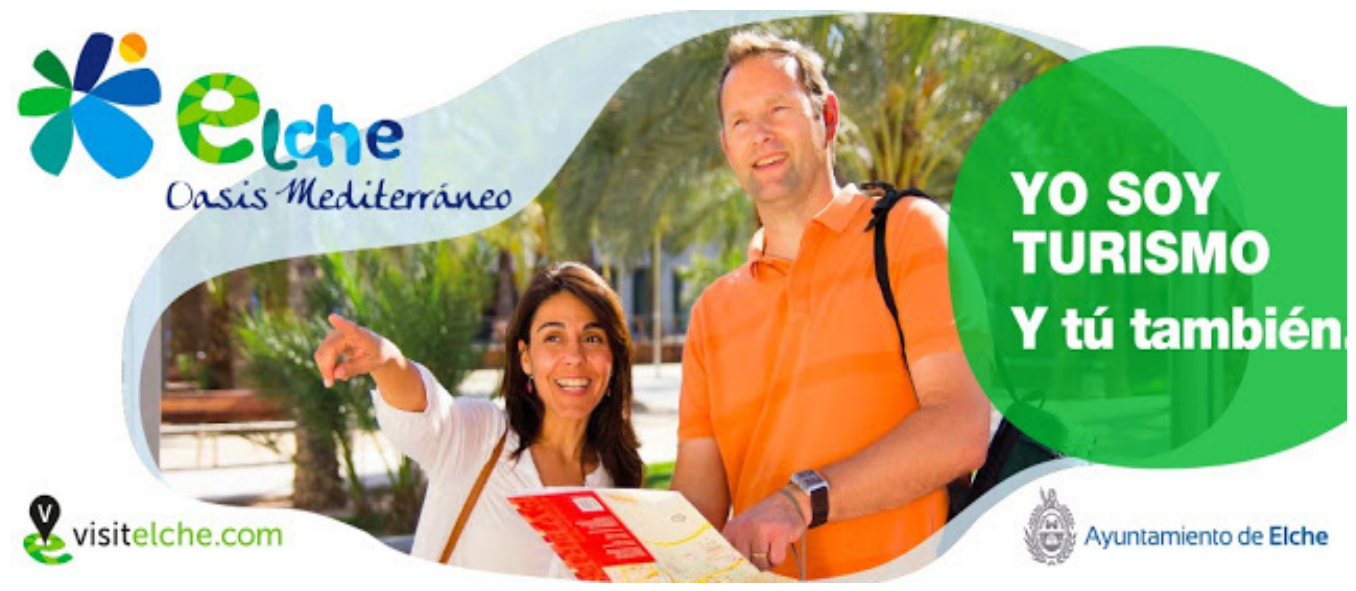

Ilustración 2: Cartel de la campaña "Nosotros somos turismo, tú también".

En definitiva, un conjunto más o menos armónico de actuaciones que, dibujado desde el plano de la construcción ideológica de lo deseable por los instrumentos más avanzados de la mercadotecnia y una terminología tecnotrópica (ie. diversificación y estructuración de productos turísticos, adecuación y creación de infraestructuras turísticas de ciudad y litoral, formación, sensibilización y emprendeduría turística, etcétera), la ampliación en el periodo 2003-2012 de la oferta hotelera de 619 plazas a 1.414, de 285 restaurantes a 362 y un incremento considerable en el número de pernoctaciones y de afiliaciones en la seguridad social en el sector de la hostelería (Turismo Elche, 2013), ciertamente han posicionado al Destino Elche en el mercado turístico nacional, y han logrado que buena parte de los ciudadanos del municipio palpen ese nuevo y repentino interés por el turismo como la Realidad. Una aceptación que se plasma en la página 5 del Informe sobre el comercio 2012 elaborado por el Observatorio socioeconómico del Ayuntamiento de Elche (Mora, 2012):

"En Elche el comercio mayorista ligado a la industria del calzado, que tiene su base en la exportación, es la actividad comercial que mejores perspectivas ofrece al igual que podría darse un factor de elevación del consumo comercial si el municipio tuviese mayor 
proyección turística dado que el turismo sigue siendo uno de los principales pilares económicos de la provincia" (Énfasis añadido).

Toda una estrategia de mediación del espacio turístico que, orquestado desde arriba, pergeña la producción de un nuevo cronotopo.

Este interés de la clase política y las élites socioeconómicas locales por la nueva base económica no ha estado exento de recelos. En los primeros compases del proceso finalesde la década de los noventa- la población todavía exigía alternativas serias a la relocalización del capital local hacia el extranjero. Ejemplo de estas exigencias fueron las violentas manifestaciones de septiembre de 2004 contra la "desleal competitividad" del empresariado chino del calzado -en las que ardieron dos almacenes de empresas asiáticas- (Martín, 2006: 475) y que resumía bastante bien el sentimiento de la población (ver Ilustración 4):

"NO a los empresarios que se llevan las fábricas al extranjero. A los empresarios que ponen 'Made in Spain' al calzado que traen de fuera. SÍ a la industria frente a los intentos del Gobierno y la UE de convertirnos en un país de camareros."

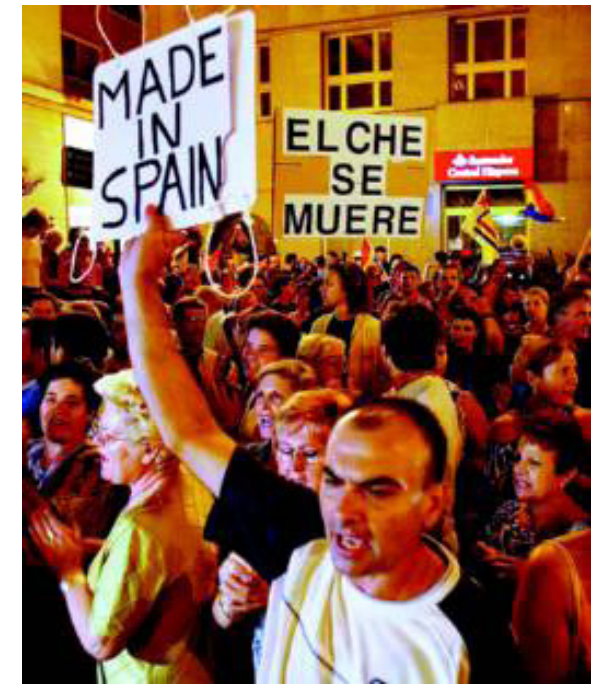

Ilustración 3

Momento de una de las manifestaciones contra la competencia china en 2004.

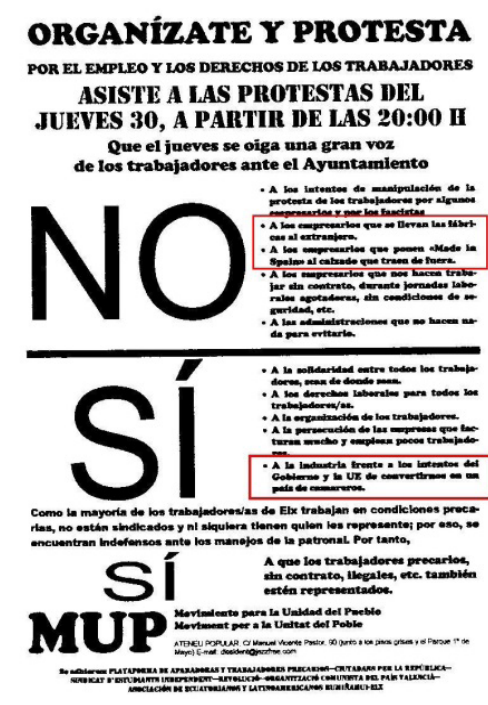

Ilustración 4

Octavilla repartida durante las manifestaciones de 2004.

Qué nos dice todo esto sobre el papel del turismo en la contextualización de las prácticas identitarias de los habitantes de un territorio (Ballesteros, 2007; Hernández, 2008; Nogués, 
2012), o de las maneras en las que dialogan distintas estrategias de desarrollo territorial en contextos turísticos nacientes en torno a los usos del patrimonio (Carmona y Nogués, 2010). Porque, ¿acaso no supone la exclusión del Museo de Pusol -primero financiera (Maciá, 2014) y después simbólica- del discurso turístico municipal, una evidencia clara de la hegemonización de la estrategia de 'poner en valor' (hacia afuera) como resorte dinamizador de los territorios a través del turismo? ¿Podría esta exclusión del Museo de Pusol mostrar la escasa relación que la ciudad de Elche siempre ha mantenido con el campo (Brotons, 1995; Larrosa, 2000: 279)? ¿Hasta qué punto el Museo de Pusol podría, de la mano de las muchas estrategias empresariales que están agrupadas en la Associació per el desenvolupament del Camp d'Elx servir como dinamizador de un territorio, al tiempo que nos habla de una nueva retórica de la ruralidad (Frigolé, 2014)? ¿Implicaría, en definitiva, la combinación de esta exclusión del museo escolar y la inclusión de una Dama ausente, un Palmeral tangible, y un Misteri protagonista una manifestación del turismo como otro elemento más de dominio sobre prácticas que, como el proyecto escolar de Pusol, miran casi exclusivamente hacia dentro? ¿Podríamos, en definitiva, confirmar con nuestro análisis que el turismo es la creación más sofisticada y perfecta del sistema capitalista porque (a) sitúa en los márgenes aquellas prácticas que "dan valor" a la cultura y anclan a las gentes a su territorio a través de la memoria (Nogués, 2006), y (b) privilegia solo aquellas cosas que, al decir de García Calvo (2006), logran convertirse en dinero de uno u otro modo?

Para responder a estas preguntas vamos a analizar los diferentes usos que se dan desde la administración pública y la percepción identitaria a estos ejemplos entre los ilicitanos a partir del trabajo de campo iniciado con 90 cuestionarios realizados de manera aleatoria a la población ilicitana entre marzo y junio de 2009, decenas de entrevistas a agentes políticos, sociales y económicos de la localidad, y la observación participante en distintos foros y contextos locales durante los últimos catorce años. Hemos estructurado el artículo mostrando la dialógica entre las condiciones macrosociales impuestas por la trayectoria socioeconómica de la localidad y la presencia simbólica de los dispositivos de dominación ideológica que condicionan lo deseable, y la realidad institucional de los grupos de interés que condicionan lo factible; y, por otro lado, por las posibilidades habilitadas desde lo microsocial que se plasman en los haceres y decires de los distintos grupos humanos sobre los cuatro elementos patrimoniales: Dama, Misteri, Palmeral y Museo. A partir de aquí, vamos a abordar cómo distintos agentes sociales luchan por controlar el capital social simbólico relativo a la representación de lo ilicitano. El foco de nuestro análisis se dirige hacia la forma en que estos agentes articulan los discursos en los que la identidad social y el patrimonio cultural se conectan como parte del proceso socio-cultural de hegemonía (Gramsci, 1975).

Esperamos invitar al lector a concluir que de la dialógica generada entre estas estructuras macrosociales, teorizadas como constrictivas, y las prácticas microsociales, consideradas 
habilitantes, en Elche ha surgido un espacio turístico que, como postula Chadefaud, "representa la proyección de los ideales y mitos de la sociedad global" (1987: 19). En otras palabras, queremos describir cómo surge un marco de referencia donde se acumulan las imágenes y valores que dan sentido, que sirven de referente y que median en la comprensión de las prácticas sociales que muestran la conversión del lugar 'Elche’a través de la mediación significativa del espacio turístico.

\section{ELCHE Y SUS PATRIMONIOS}

Elche es una ciudad de tamaño medio (230.224 habitantes, [INE de 2013]) localizada en la provincia de Alicante. Durante años fue conocida como la "Ciudad de las Palmeras" o la "Jerusalén de Occidente" (Martínez, 2003: 29) y también, aunque en bastante menor medida, como la "Ciudad del Misteri", en referencia al drama sacro-lírico que constituye el núcleo de sus fiestas locales. Desde 1897 se le conoce también como la "Ciudad de la Dama" gracias al descubrimiento de un busto datado en época Íbera, y bautizado precisamente como "Dama de Elche".

Palmeral, Dama y Misteri constituyen una auténtica tríada simbólica. Los dos primeros declarados Patrimonio de la Humanidad por la UNESCO, mientras la Dama, estrella del Museo Arqueológico Nacional, es el elemento más representado en la ciudad, y auténtico icono plasmado en fotos, composiciones pictóricas, esculturas, nombres de empresas, equipos deportivos, etc.

Por supuesto que lo que desde las instituciones y la expertez se denomina el "repertorio patrimonial de la ciudad" es más amplio, e incluye elementos de empaque como el yacimiento arqueológico de la Alcudia, donde fue hallada la Dama de Elche; la basílica de Santa María; el Castillo de Altamira, una importante residencia nobiliaria construida sobre los restos de una antigua fortaleza islámica; la Calahorra, una torre defensiva que protegía la entrada a la Elche islámica (Ilch); y el Museo Agrícola de Pusol. Sin embargo, no todos estos elementos del "repertorio patrimonial de la ciudad" pueden ser considerados referentes identitarios o, al menos, no del mismo modo y al mismo nivel que la tríada antes mencionada.

Junto a estos, también hay referentes identitarios que no tiene la etiqueta de "patrimonio cultural" pese a ser muy reconocidos por la sociedad ilicitana. Uno de los mejores ejemplos es el Elche C.F. Otros ejemplos son el "arroz con costra"; el valenciano, lengua vernácula, o la industria del calzado que, le ha valido también el apelativo de la "Ciudad del Calzado" (San Miguel, 2000; 2002). No obstante, todos estos referentes no poseen la misma potencia representativa de la identidad ilicitana; incluso uno de los que en la mayor parte de los grupos culturales se considerara esencial como es la lengua, parece haber sido olvidado en el caso de Elche (Larrosa, 2000: 258). 
Podemos afirmar que todos los elementos que hoy distinguen a Elche como ciudad son elementos patrimoniales en los planos nacional e internacional así como referentes identitarios para la población ilicitana. Es decir, estos elementos son los depositarios simbólicos de lo que significa pertenecer a un determinado grupo. Porque, como afirma Frondizi, "los valores no existen por sí mismos, al menos en este mundo: necesitan de un depositario en que descansar. Se nos aparecen, por lo tanto, como meras cualidades de esos depositarios." (1958: 17). Entonces, ¿por qué y, sobre todo, cómo han llegado estos tres elementos esenciales a representar a la sociedad ilicitana y se ha excluido a otros? ¿Fueron primero referentes identitarios antes de ser reconocidos como "patrimonio cultural" o, al contrario, son referentes identitarios porque han sido reconocidos como patrimonio? ¿Facilita el proceso de conversión del lugar a través del espacio turístico la transformación de los referentes identitarios en elementos patrimoniales? O por el contrario, ¿pierden los elementos reconocidos internacionalmente como "patrimonio cultural" potencia identitaria al devenir atractivo para turistas? Para aclarar estas preguntas, fundamentales en nuestro estudio, examinamos los distintos contextos socioculturales en los que estos elementos se forjaron como referentes identitarios, como patrimonio cultural y, finalmente, como recursos turísticos. La descripción histórica abarca desde las últimas décadas del siglo XIX hasta las últimas del XX, y viene enmarcado por ese proceso de cambio global que Eisenstadt denomina "Modernización", y tiene como rasgos principales la Industrialización y la emergencia del Estado-Nación como nueva unidad de soberanía política y foco de identidad política y cultural (1966: 1-10).

Debemos hacer, sin embargo, dos precisiones conceptuales antes de continuar. La primera refiere a qué entendemos por "Patrimonio Cultural". Para esto acudiremos a la definición que ofrece la UNESCO, que es la institución que monopoliza el sello legitimador y gestiona el nomenclátor a nivel mundial: "Heritage is our legacy from the past, what we live with today, and what we passon to future generations. Our cultural and natural heritages are both irreplaceable sources of life and inspiration" (UNESCO, 19922014). Es un concepto que, en su amplitud, puede abarcar cualquiera de los elementos que dan sentido a la vida de los grupos culturales. Sin embargo, cabe recordar que el patrimonio cultural ha devenido, también, en una categoría legal bastante restrictiva.

Desde el análisis socioantropológico, la inclusión de un elemento en la categoría "patrimonio" supone una legitimación de su capital simbólico y lo convierte, como afirma García García (1998), en "producto metacultural", en una metonimia que representa a ese todo que es la cultura que una vez lo produjo. Sin embargo, el elemento patrimonial no puede hablar por sí mismo. Necesita relacionarse con un discurso que se articula desde el presente y está en constante reconstrucción, para de este modo hacer hablar al elemento y hacerlo comprensible a todos. Por este motivo, los elementos patrimoniales se disponen para conformar un repertorio referido a un contexto particular y materializar 
así un discurso específico, o como Prats dice: "[...] escoger determinados referentes [...] y exponerlos de una u otra forma. Evidentemente, esto equivale a articular un discurso que quedará avalado por la sacralidad de los referentes." (1997: 31-32). Porque cuando se dirige el discurso a hablar sobre un territorio y/o sociedad que lo ocupa, se enfatizan las características comunes relativas a este.

La segunda precisión es sobre la construcción de identidades colectivas en las sociedades complejas que, para Eisenstadt, es un factor común del proceso de Modernización (1966: 10-11). Esta identidad compleja se construye sobre el sentido de pertenencia a una entidad superior, tal que un Estado-nación (Gellner, 1995: 52). Esta construcción se nutre de un conjunto de previas referencias y, como ocurre en el caso del patrimonio cultural, de las que tan solo unos pocos elementos son seleccionados para representar al colectivo y servir como depositarios de la identidad.

Así, hemos diferenciado, grosso modo y de la manera más clásica, los dos discursos -o formas de vida (Bajtín, 1965)- que dialogan en la producción de identidad y de sus referencias patrimoniales: el popular y el oficial. El discurso oficial lo encontramos en las instituciones locales, controladas durante el siglo XIX y buena parte del XX por la burguesía y la clase media alta, aunque desde el último tercio del siglo XX corresponde más a una clase media-media (Moreno, 2006: 271-273). Por su parte, el discurso popular se construye en unas prácticas cotidianas de los habitantes que, aun basadas en el discurso oficial, se le oponen en ocasiones. Una relación dialógica que no excluye, más bien al contrario, la existencia de conflictos por significar cada uno de los referentesidentitarios y de los elementos del repertorio patrimonial de la ciudad, especialmente en el nuevo contexto generado por el interés de las autoridades municipales por el turismo como una actividad económica que conforme la ciudad.

\section{LA JERUSALÉN DE OCCIDENTE, CIUDAD DEL PECADO PATRIMONIAL}

Este proceso comienza con el denominado "caso de la Dama de Elche": un escándalo con connotaciones de expolio colonial que constituye todo un pecado original patrimonial por cuanto va a condicionar, cuando no a determinar, los ulteriores procesos de patrimonialización.

Hacia finales del siglo XIX, en la ciudad de Elche comienza un incipiente desarrollo industrial basado en la fabricación de espardenyas (alpargatas de esparto) (Miranda, 1991: 43-44). Elche ya era entonces una población de cierta importancia en la provincia de Alicante (23.847 habitantes en el censo de 1887, según el INE) y renombrada por sus palmeras gracias a los viajeros que la habían visitado durante el último tercio del siglo XVIII y el siglo XIX. Aquellos viajeros, principalmente franceses e ingleses, quedaron 
impresionados por el paisaje de oasis de la ciudad e hicieron de éste un hito del naciente mito romántico del exotismo español²:

"We flopped at Elche, a large town belonging to the duke of Arkos, built on the skirts of a wood, or rather forest, of palm-trees, when the dates hanging on all fides in clufters of an orange colour, and the men swinging on the bafs ropes to gather them formed a very curious and agreeable fcene. The palm(s) are old and lofty: their number is faid to exceed two hundred thousand" (Swinburne, 1779: 118).

Sin embargo, aunque eran las palmeras las que distinguían a Elche desde fuera y hacia afuera por cuanto los libros fueron escritos por extranjeros y estaban destinados al público europeo, los ilicitanos identificaban su ciudad desde dentro como asuncionista; como la localidad elegida por la Virgen de la Asunción frente a otras ciudades vecinas con las que competía, y en especial frente a la capital provincial (Rodríguez, 2013: 121). Es en este contexto de competencia vecinal en el que irrumpe, y por tanto en el que se debe entender, el affaire de la Dama de Elche.

\subsection{LA DAMA DE ELCHE}

El 4 de agosto de 1897 enla finca agrícola de La Alcudia se descubre un busto escultórico en el transcurso de unos trabajos de nivelación de la parcela. Faltaban exactamente diez días para la representación anual del Misteri y la noticia corrió como la pólvora. Desde aquel mismo día el busto fue bautizado como "La Reina Mora" y recibido con gran entusiasmo por unos ilicitanos que en su mayoría trabajaban en la alpargata:

"Les casinos, les tertulias du soir chantaient la gloire du buste à la maison, à la boutique, à l'atelier; tous les confectionneurs d'espadrilles, c'est-à-dire tous les Ilicitans, en parlaient en poussant lalène dans les semelles de corde. Sa photographie brillait en belle place dans le comedor de l'Hôtel de la Confianza, suprême honneur et consécration suprême. Le buste devenait vraiment l'idole de la ville." (Paris, 1910: 82).

La curiosidad popular llegó a tal extremo que los propietarios de La Alcudia, el médico Manuel Campello y su esposa $\mathrm{M}^{\mathrm{a}}$ Asunción Ibarra, decidieron mostrar el Busto en el balcón de su casa durante algunos días. Colas de curiosos desfilaron para contemplar la misteriosa escultura. Ante la sorpresa general, el doctor Campello la vendió a Pierre Paris, un profesor y arqueólogo francés que la llevó al Museo del Louvre. La venta fue sentida como un expolio por toda la población, tal como el propio Pierre Paris dejara por escrito años más tarde, elogiando la actitud del pueblo hacia un busto al que ya consideraban su "patrimonio común": "À la nouvelle de marché conclu, toute la ville a été fort désagréablement surprise; on considérait la statue comme un patrimoine commun, la dame faisaittort à la patronne, notre dame de l'Assomption." (Tortosa, 1996: 222). El

2. En esta cita de Swinburne hemos respetado la ortografía del original. 
escándalo se convirtió en afrenta nacional. Una campaña en prensa reclamó el final de la alienación del patrimonio nacional, cuya principal repercusión fue años más tarde, la primera ley española de patrimonio arqueológico (Ley del 7 de julio de 1911) (Tortosa, 1996: 222).

La aparición del Busto -escándalo incluido- tuvo una honda repercusión en el país ya que la Dama devino prototipo de la feminidad alternativo al estereotipo de la Carmen de Mérimée y Bizet. La Dama devino pues símbolo del "alma hispana" en un momento en el que, precisamente, el país vivía una fuerte crisis de identidad causada por el conflicto en Filipinas y Cuba, últimos restos de pasadas glorias coloniales, e indicador inequívoco del estatus de actor secundario que había alcanzado España en el concierto europeo (Olmos y Tortosa, 1996: 220).

Desde su venta, la ciudad no ha dejado de añorar a su amada "Dama", apelativo que recibió, por cierto, tras su llegada al Louvre, pues hasta entonces los eruditos la llamaban "el Busto de Elche" y los ilicitanos "la Reina Mora". Nunca hubo manifestaciones en las calles clamando por su vuelta, reclamaciones del Ayuntamiento ni una repentina concienciación por el patrimonio; algo inconcebible por otra parte, teniendo en cuenta el momento histórico. Simplemente se impuso la lógica de la propiedad privada: nadie cuestionó el derecho de Campello a disponer de algo que a todos los efectos les pertenecía. Sin embargo, el sentimiento generalizado de expolio de lo que identificaba a todo un pueblo, constituye el sustrato de una conciencia germinal sobre la necesidad de proteger el -en terminología del momento- "Tesoro Nacional".

Desde su vuelta a España en 1941 el Busto ha permanecido en el Museo Arqueológico Nacional en Madrid y solo ha visitado Elche en dos ocasiones: 1965 y 2006. A pesar de esto, parecía que la "Ciudad de las Palmeras" era solo la "Ciudad de la Dama", mientras el Palmeral languidecía y era, literalmente, relegado a un segundo plano.

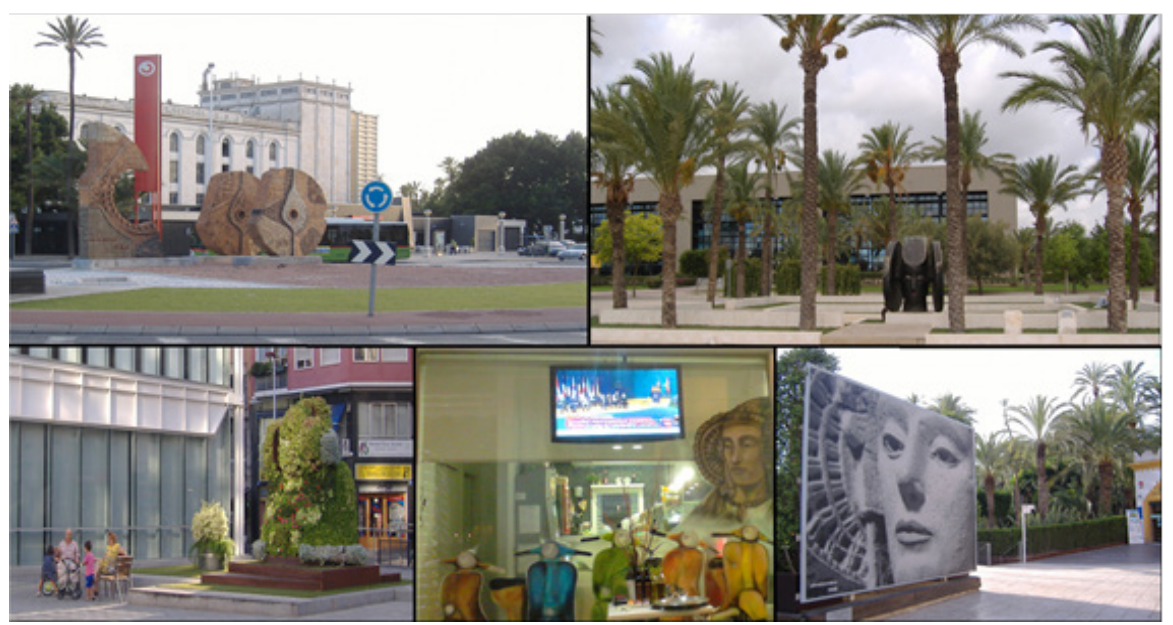

Ilustración 5: Diferentes iconos de la Dama de Elche (Archivo personal autores). 


\subsection{EL PALMERAL}

Hasta las últimas décadas del siglo XIX la agricultura había sido la base económica de Elche, y en ese sistema de producción, las palmeras junto a las acequias desempeñaban un papel fundamental porque eran los componentes esenciales de un sistema agrícola -el oasis artificial- establecido hacia finales del siglo X por el Califato Omeya, y continuado tres siglos después por los habitantes cristianos tras la conquista y repoblación de la ciudad (Martínez, 2003: 26). El oasis artificial está pensado para mitigar los efectos de la intensa evapo-transpiración y radiación solar sobre los cultivos en áreas desérticas o semidesérticas. Las palmeras se plantan acotando parcelas rectangulares, en las que se cultivan forrajeras, frutales, cereales y hortalizas. La palmera no constituye un cultivo en sí misma, aunque sus palmas se utilicen en el Domingo de Ramos y sus dátiles se consuman por gran parte de la población y del ganado (Martínez, 2003: 22-26).

La transformación de Elche a finales del XIX en ciudad productora de alpargatas coincide con la irreversible decadencia del palmeral como sistema agrícola (Miranda, 1991: 139-140). Este retroceso del papel económico de la palmera contrasta con la renovada imagen de "bosque de palmeras" o "palmeral" como paisaje "natural" que venía siendo activada desde hacía décadas por los viajeros románticos (Larrosa, 2003:81). Elche se consagra como un rincón exótico propio de Asia o Palestina, aunque en el sudeste español, atrayendo a los más selectos e ilustres visitantes, entre los cuales aparecen reyes españoles como Amadeo de Saboya y Alfonso XIII, y el que fuera su dictador, Miguel Primo de Rivera, o a la emperatriz Elisabeth de Wittelsbach, más conocida como Sissí (Ramos, 1989: 336).

Esta exótica imagen de Elche se ve amenazada directamente por el crecimiento urbano de las primeras décadas del XX. La posición de los huertos de palmeras a modo de cinturón en torno al recinto urbano, los convertía en necesarios y potenciales solares para la expansión de la ciudad (Gozálvez, 2006:48), de modo que la cuestión no tardó en plantearse: ¿Era realmente necesario sacrificar los huertos de palmeras en aras del progreso? ¿Podría permitirse otro affaire Dama de Elche?

El mismo erudito local que estuvo implicado en el asunto de la Dama, Pere Ibarra, fue una de las figuras más destacada en la lucha contra la destrucción del Palmeral (Castaño, 1998: 54). Sin embargo, las demandas de protección no encontraron satisfacción hasta la II República cuando, por decreto de 8 de marzo de 1933, se prohibía el corte de palmeras vivas en Elche con la intención de preservar su característico paisaje (Jaén, 1989: 158). El decreto creaba asimismo el Patronato del Palmeral, que sería la fundación encargada de supervisarlo y gestionarlo ya que la mayoría de los huertos de palmeras eran privados. Lamentablemente este decreto, en vigor hasta 1986, fue escasamente aplicado tras la Guerra Civil y, de hecho, el Patronato del Palmeral solo empezó a trabajar en 1982 (Larrosa, 2003: 86). 


\subsection{EL MISTERI}

En 1931, apenas dos años antes del decreto del Palmeral, el Misteri o Festa d'Elx, que es la denominación local, había sido declarado Monumento Nacional, y se constituía así en el primer "monumento" no material en ser reconocido como tal (Rodríguez, 2013: 107). Con esta declaración se colocaba al Misteri bajo el control estatal de la Junta Nacional de Música y Teatros Líricos, aunque su presidente, el músico Óscar Esplá, también creó una junta local, el patronato de la Festa, más operativo en la organización de las representaciones en la localidad.

La razón aducida para proteger al Misteri, competencia municipal desde el siglo XV, fue la decadencia artística en la que estaba sumido desde el último tercio del siglo XIX. A esta se añaden, en el XX, constantes apuros económicos que generan, a su vez, numerosos enfrentamientos políticos (Rodríguez, 2013: 99-100). La protección gubernamental se percibía como la única solución posible para evitar su completa desaparición (Cremades, 2011: 56-57). A la cabeza de las reivindicaciones para restaurar el esplendor original se encuentra Pere Ibarra, acompañado de otras figuras notables como el propio Esplá (Castaño, 1998:56).

El régimen franquista, por su parte, dotó al Misteri de un órgano de gobierno estable, el Patronato Nacional del Misterio de Elche (1948), que funcionaría hasta 2005 con una sola modificación en 1986 para aumentar el número de sus miembros. La normalización legal de este patronato y su normativa, recogida en la ley del Misteri de Elx (13/2005 de 22 de diciembre de la Generalitat) fue asumida como un compromiso por parte del cabildo en su candidatura como Patrimonio de la Humanidad a la UNESCO (Cremades, 2011: 62).

\subsection{LA DESINDUSTRIALIZACIÓN: DEL TURISMO A LA UNESCO Y VICEVERSA}

Los treinta últimos años han venido marcados por la acelerada desindustrialización del municipio (Martín, 2006: 472-73). La industria del calzado, continuadora de la de la espardenya y motor del espectacular crecimiento de la ciudad durante las décadas de los cincuenta y sesenta (San Miguel, 2002: 71-73), comienza su declive a principios de los ochenta (Palazón, 1989: 193-194). En los noventa el zapato ilicitano tuvo que competir, entre otros países asiáticos, con China. Muchos empresarios relocalizaron sus fábricas para abaratar costes de producción. El trabajo escaseó en la ciudad y muchas empresas y talleres tuvieron que cerrar (Martín, 2006: 477). Tras aquella dura reestructuración, un menor número de empresas ilicitanas, aunque de mayor tamaño, siguen fabricando zapatos en la localidad. Según las estadísticas oficiales de población activa por sectores económicos, Elche deja de ser una población industrial a finales del siglo XX (Cutillas, 2006: 60). Para hacer frente a esta situación, el gobierno municipal (PSOE) diseñó un 
plan de diversificación económica Futurelx (1998-2011), enmarcado en los principios de un desarrollo sostenible que apostaba por la estrategia de "marca-ciudad" en torno a los dos principales elementos patrimoniales: el Palmeral y el Misteri. Uno de los objetivos declarados de este plan era la atracción de turismo cultural (Ayuntamiento de Elche, 2009: 1). Muy pronto, comenzaron los contactos políticos para promover ante la UNESCO la candidatura de ambos elementos como Patrimonio de la Humanidad. El reconocimiento de ambos como Patrimonio Mundial señala un nuevo hito del proceso de distinción y representación identitaria: el del reconocimiento a nivel planetario.

Desde el Ayuntamiento de Elche las estrategias políticas de promoción de la ciudad acuñaron lemas como "ciudad de los dos Patrimonios de la Humanidad" representado por un logo-símbolo que incluye una palmera y la Magrana del Misteri ${ }^{3}$. Se organizaron acontecimientos como "la Visita de la Dama" en 2006, con ocasión de la inauguración del Museo Arqueológico e Histórico de Elche (MAHE) y la reapertura tras décadas cerrado del castillo de Altamira, donde se expuso aquella. El éxito fue espectacular: más de 380.000 visitantes según cifras oficiales que marcaron un punto de inflexión en la transformación de la ciudad en destino turístico.

La inclusión del Palmeral y del Misteri en la Lista de Patrimonios de la Humanidad ha repercutido en la valoración que los habitantes locales hacen de estos dos elementos; si bien el sector empresarial de la ciudad aún duda de su capacidad para atraer turismo (Carmona y Nogués, 2010: 775-776).

Las consecuencias más palpables se manifiestan sobrelos propios elementos. Para el Misteri ha supuesto su internacionalización definitiva, lo que a su vez, ha permitido formalizar los tres ensayos generales previos a la representación anual que los convierte de facto en nuevas oportunidades de asistencia para un público atraído por el reconocimiento UNESCO. Como colofón, en 2006 se renueva y reinaugura el museo de la Festa (abierto en 1997) con el objetivo de difundir el Misteri entre aquellos visitantes que no acuden a la ciudad durante las representaciones de agosto.

El Palmeral también se ha visto beneficiado directamente de su declaración UNESCO. Así, en 2005 se inauguró un museo y centro de interpretación en la casa del antiguo huerto de San Plácido, en donde también se acoge al Taller municipal de Palma Blanca creado en 1998 para transmitir este saber que está en manos de un grupo reducido de familias ilicitanas. Este museo es, además, la salida y llegada de la creada Ruta del Palmeral: un recorrido señalizado entre los huertos históricos. La influencia social de los reconocimientos UNESCO se manifiesta también en otras instituciones de la ciudad, caso de la Universitas Miguel Hernández, que ha creado cátedras institucionales dedicadas a la tríada identitaria: Misteri (2004), Palmeral (2013) y Dama (2014).

3. La Magrana, pronunciada popularmente Mangrana ("granada" en valenciano) a causa de su parecido con la fruta, es un artefacto aéreo que desciende desde el techo de la basílica de Santa María, durante la representación del Misteri, llevando a ángeles que cantan y tocan el arpa y la guitarra 
Por su parte, el Museo de Pusol, pese a ser el tercer elemento reconocido por la UNESCO, no parece que se haya beneficiado ni tanto ni tan directamente como los otros dos. Este Museo nace en 1969, momento álgido del desarrollismo local, a iniciativa de un maestro rural, Fernando García Fontanet, con el objetivo de difundir y conservar la cultura tradicional del Campd'Elx amenazada por los procesos de modernización. Tras más de cuarenta años de existencia el museo ha logrado mucho más que su inclusión en el registro UNESCO de Buenas Prácticas en 2009 o premios como el de Europa Nostra en 2010. Es un proyecto pedagógico en el que los alumnos del colegio aprenden la cultura tradicional directamente de sus mayores y son los encargados de explicarla a los visitantes. Una práctica museográfica que hace que este sea el museo más vivo y con mayor implicación comunitaria de todos los que hay en el municipio. A pesar de estas fortalezas no ha logrado, sin embargo, ser incorporado en los discursos identitarios oficial o popular, ni obtener la repercusión institucional que se merece, ni tener una consideración de recurso turístico equivalente al Misteri o al Palmeral (Ayuntamiento de Elche, 2009: 9).

\section{DEL TÓTEM IDENTITARIO A LA REPATRIMONIALIZACIÓN}

Coincidimos con Appadurai en que la identidad basada en la distinción es la única forma de existencia en nuestro mundo globalizado, y en que el concepto 'cultura' sirve más para hablar de las diferencias entre los grupos humanos que para indicar una realidad sustantiva (1990: 295). La identidad, en este marco, es entendida como una respuesta a la presión de la homogeneización, como la manera en la que algunas comunidades despliegan sus estrategias de distinción utilizando los mismos elementos que constituyen ese proceso de homogeneización. Unas estrategias que, analizadas, muestran que cuando hablamos de "cultura" (sustantivo) seríamos más precisos si la abordásemos como adjetivo y hablásemos de "lo cultural" como manera de hablar de la diferencia, como forma de distinguir a unos grupos humanos de otros (Appadurai, 1996: 12). En el caso de Elche esta distinción es el resultado de un proceso de selección de elementos que la identifican y distinguen en un contexto turístico. Para facilitar la comprensión del proceso vamos a trazar algunas etapas.

En primer lugar podemos hablar de una etapa proto-turística que se correspondería con los siglos XVIII y la mayor parte del XIX, en la que la distinción identificativa de Elche procede del exterior (visitantes, viajeros y forasteros). Durante esa etapa Elche es dibujada como la "Ciudad de las Palmeras" y los documentos muestran cómo estas denominaciones son asumidas por los ilicitanos para distinguir su localidad de las del entorno provincial y, también, para contraponerla a la tradicional identidad asuncionista que estaba bajo el control simbólico de los estratos sociales más enriquecidos.

La segunda etapa, finales del siglo XIX hasta el final de la Guerra Civil, está marcada por la figura de la Dama y coincide con el momento en el que Elche experimenta 
cambios importantes y la industrialización se consolida (San Miguel, 2002: 75). El descubrimiento e inmediata apropiación simbólica del busto por parte del pueblo, en especial su proletariado, señala un giro en la construcción simbólica de la identidad. Esta apropiación, se plasmó no solo en la cola de curiosos para contemplarla, sino en la pronta denominación popular de "Reina Mora" y en el disgusto que produjo su venta. Una forma de entender el patrimonio cultural "desde abajo" en la que la atribución de valor se realiza más en función de la identidad que del conocimiento elitista de la Historia, el Arte, o de cualquier otra disciplina académica. Aquella expresión de sentimiento identitario sirvió a los individuos mejor formados y eruditos de la sociedad local, de los que Pere Ibarra es el mejor ejemplo, para articular un discurso más elaborado y orientado a una defensa del patrimonio local entendido en susentido actual, y que incorporó al sentir popular usos y elementos más propios de las disciplinas académicas como fueron los documentos del archivo histórico.

El trauma provocado por la venta consagró a la Dama como el símbolo ilicitano par excellence, superando incluso a las cotidianas palmeras. Por una parte, el escándalo mediático le había dado la repercusión necesaria para que el Busto fuera conocido a nivel nacional, y había situado a Elche en el mapa del mundo. Por otro lado, la posterior adopción de la Dama como símbolo de lo nacional, incorporada a los discursos políticos de sesgo regeneracionista -y más tarde al franquista- le confiere un valor añadido: la representación de la identidad local en clave nacional, de lo que se desprendían también derivaciones inevitables para España como Estado inmerso en un proceso de modernización. En este caso, la necesidad de convertir en cuestión de Estado la protección de algo a lo que solo una minoría culta daba valor, el patrimonio o, mejor dicho, lo que entonces se entendía por tal, frente a terceros. En este sentido resultó decisivo el contexto histórico internacional en el que estaba en pleno auge la formación de imperios coloniales. No solo porque permite comprender el sentimiento nacional de expolio que desencadena la venta de la Dama en función de lo que, utilizando la terminología de Wallerstein (2004), llamaríamos la posición semi-periférica de España respecto a las potencias europeas, sino (y especialmente) porque la posesión y mantenimiento de un Tesoro histórico-artístico se veía como uno de esos rasgos de prestigio que señala y legitima el estatus de país europeo central al que aspiraba España.

Para Elche, encarnación de los problemas patrimoniales del país, el corolario inevitable fue la exigencia de protección legal de sus referentes identitarios. La protección estatal constituía la única defensa posible contra su deterioro, destrucción o expolio por parte de potencias extranjeras. Podría decirse que fue una estrategia de la élite ilustrada local la que finalmente triunfará con los decretos del Misteri (1931) y del Palmeral (1933), y que materializaron lo que entonces se entendía por "patrimonialización": un proceso administrativo de inclusión de bienes culturales dentro de la categoría legal de patrimonio 
para protegerlos, conservarlos, exhibirlos y difundirlos (Jeudy, 1990). Además, una patrimonialización pionera, teniendo en cuenta que la falta de una ley patrimonial más amplia y específica obligó a encajar al Misteri como "monumento" y al Palmeral solo le evita el talado de palmeras.

La tercera etapa, coincidente con el desarrollismo franquista, la situamos entre los años cuarenta y los ochenta, especialmente en los sesenta. Elche alcanzaba proporciones de gran ciudad hasta el punto de convertirse en uno de los milagros de los Planes de Desarrollo, pasando de 56.341 habitantes en 1950 a 164.779 en 1981 . Este crecimiento fue posible gracias a una industria del calzado que atrajo la llegada de fuertes contingentes de mano de obra inmigrante en su mayoría castellano parlante (Larrosa, 2000: 258;) y a la que los locales llamaron "els forasters" (Mora, 2006: 64). Un informante resumía la celeridad del proceso con estas palabras: "En aquella época, llegabas con la maleta y te alojabas en casa de un amigo o familiar. Al día siguiente empezabas a trabajar en la fábrica y al otro te comprabas un piso".

La intensificación de este proceso de modernización supuso en la estructura social el aumento y afianzamiento de las clases trabajadora y media (Sanz, 2006: 373-377); al tiempo que culminaba la castellanización de la población tras dos siglos de progresiva influencia y con el refuerzo nada despreciable de la prohibición franquista de utilizar otra lengua que no fuera el castellano.

En estas circunstancias, la tríada identitaria ilicitana demostró una gran capacidad para integrar todos esos nuevos componentes socioculturales y evitó en gran medida los rechazos, ya que favoreció la generación de un cierto consenso entre los diferentes grupos y agentes sociales. La patrimonialización había consagrado tres auténticos tótems (Territorio-Palmeral, Historia-Dama y Fiesta-Misteri) que representan a una comunidad atemporal y, por tanto, esencialmente virtual e imaginada, pero que asegura su continuidad precisamente por quedar al margen del cambio. En esta maleabilidad discursiva radica su mayor ventaja: en la utilización de esencialismos que sugieren sin concretar lo que significa ser ilicitano. Así, el discurso y las prácticas oficiales potenciarían los elementos de la tríada, a pesar de la ausencia de la Dama (suplida con multitud de reproducciones), las restricciones de participación e incluso de público que imponían las representaciones del Misteri, y el constante inconveniente que supuso el Palmeral para la expansión urbana que se derivó de la llegada de mano de obra inmigrada. Mientras tanto, la lengua valenciana era sustituida y/o relegada en tanto que elemento potencialmente conflictivo con la nueva composición sociocultural de la ciudad, aunque el Camp d'Elx se mantendrá como área valenciano parlante hasta los años noventa, al quedar el ámbito rural en gran medida fuera de la expansión urbana (Larrosa, 2000: 258). Esto explica como para muchos residentes en Elche, ser ilicitano no significa ser valenciano (Carmona y Nogués, 2010: 771). 
En este sentido, resulta reveladora la evolución de la propia tríada identitaria. Por una parte, la progresiva castellanización de los nombres. Buen ejemplo es el Misteri que en el XX se castellanizará como "Misterio de Elche" junto a otras celebraciones de las fiestas patronales, caso de la Nit de l'Albà que pasa a Noche de la Alborada; otras reciben directamente sus nombres en castellano al alcanzar entidad propia, como la "Guerra de las carretillas", una batalla campal a base de petardos borrachos que se desarrolla tras la Nit de l'Albá. El Palmeral, conformado como idea entre el XIX y el XX, nunca tuvo denominación en valenciano, mientras el vocabulario de las labores propias del cuidado de las palmeras, todo en valenciano, ha ido desapareciendo conforme lo hacía su antigua función agrícola. Por otro lado, otras celebraciones adquieren nuevas formas y significados aunque mantengan el nombre tradicional (caso de la Roà) ${ }^{4}$, mientras el Misteri, con diversos altibajos, continuaría la senda de la institucionalización iniciada con su patrimonialización, en aras de una representación más cuidada y en detrimento de su vertiente más lúdica, tal y como indica que se le comience a definir como "drama sacro-lírico" (Rodríguez, 2013:104).

La cuarta y última etapa comienza en los noventa, y se caracteriza por la progresiva desindustrialización del tejido productivo local en un mundo global que, inducido por la modernización, se antoja inseguro e impredecible (Beck, 1998) y que, paralelamente, ha devenido en una "sociedad cada vez más preocupada por el futuro (y por la seguridad) que implica la noción de riesgo" (Giddens, 1998: 27). La búsqueda de alternativas a estos retos desde lo local viene marcada por unas dinámicas globalizadoras, como son la noción de "desarrollo sostenible" que ha derivado en la resignificación de la 'naturaleza' en 'medioambiente' y en la utilización del 'patrimonio cultural' como recurso para el turismo (Nogués, 2002: 148). Un nuevo maná que, de esta forma, permite mantener la heterogeneidad cultural frente a la homogeneización que comporta la globalización vía ingresos dinerarios para afrontar las incertidumbres del futuro. En este contexto, este discurso oficial reactiva el progreso desde fuera hacia dentro en un proceso de representación identitaria, y lo hace además a través del patrimonio cultural, ahora ya una auténtica institución con una importante dimensión legal y pretendida vigencia planetaria. Dimensión legal que, claro está, obliga a la asunción del discurso por parte de las administraciones competentes para llevarla a la práctica.

4. La procesión de la Roà (del verbo rodar, pero con pérdida de "d" intervocálica) y consiste en "dar vueltas" a modo de velatorio (Castaño, 2010: 30). Tiene lugar el día 15 de agosto de madrugada, recorriendo (generalmente más de una vez) con un cirio alumbrado el mismo itinerario que a la mañana siguiente seguirá la procesión del entierro, esto es, las calles que antaño ocupara el circuito de murallas de la antigua Vila Murada (Llobregat, 1977: 56). Desde al menos tres décadas, esta procesión convive con una fiesta masiva por todo el centro de la ciudad, en la que se bebe y se baila en las diferentes barracas festeras y locales de ocio hasta la salida del sol. 
Así pues, asumido el discurso globalizador del turismo por parte del gobierno local, la conclusión lógica es que para atraer turismo hay que apostar por lo que distingue y hace único a lo local en el mercado global; esto es, los elementos identitarios más importantes de la ciudad. El siguiente paso era, por tanto, una operación de mercadotecnia, una "puesta en valor" que situara a los elementos en el escaparate mundial. Si tomamos el término patrimonialización en el sentido que hoy tiene en la literatura científica, podemos afirmar que Palmeral y Misteri fueron repatrimonializados.

El éxito de esta repatrimonialización, con las dos inclusiones UNESCO, ha redundado en la influencia que el discurso oficial ejerce sobre el popular, reafirmando la línea identitaria representada por la tríada. En la práctica, esto ha supuesto un incremento de la valoración social del Palmeral y el Misteri, y también del resto de patrimonio local, cultural o natural, en un momento de especulación inmobiliaria, llegada de inmigración extranjera y de crecimiento demográfico sostenido e intenso y posterior crisis económica (Ayuntamiento de Elche, 2013). Esta valoración de la tríada se manifiesta en la apropiación popular de los iconos diseñados para la estrategia de marca-ciudad, así como en la reclamación explícita de la vuelta de la Dama que se ha asumido por los representantes políticos locales y es utilizada como argumento en la lucha partidista.

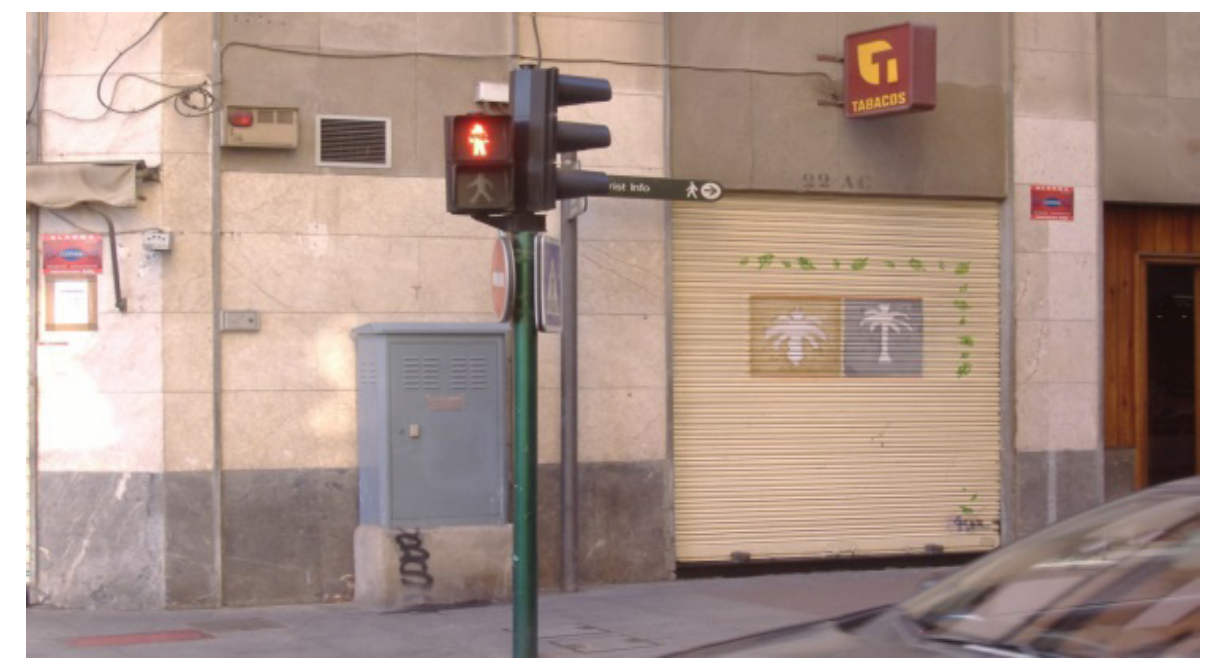

Ilustración 6: El logo oficial de los “Ciudad de los Dos Patrimonios de la Humanidad”, compuesto por un icono del Misteri (izquierda) y otro del Palmeral (derecha), popularizados en una relación dialógica.

Esto último nos previene de las dificultades y tensiones en las que este proceso dialógico continúa inmerso. Por una parte, mientras el discurso oficial ha encontrado una potente fuente de legitimación en las políticas de la transformación de la ciudad en destino turístico (o si se prefiere, de "puesta en valor"), los argumentos que conceden capacidad económica al patrimonio han calado muy escasamente en el discurso popular que sigue concibiendo a Elche como "ciudad industrial", categoría excluyente e incompatible con la 
de "ciudad turística". Elche es fábricas y talleres de calzado (muchas veces clandestinos); bolsas de faena en los postigos (zaguanes) y aparadoras trabajando en casa; el sobre marrón con el jornal del viernes y el agosto cerrado por vacaciones. En definitiva, Elche es lo que constituyó su fuente de riqueza y bienestar: "fábricas de zapatos", y a ello habría que volver aunque todos saben que ese barco ya zarpó. Prueba de esto es que, quizá ya desde la resignación, se acaricia la idea de patrimonializar la fabricación de zapatos e incorporarla a la tríada identitaria (ver la ilustración 7).

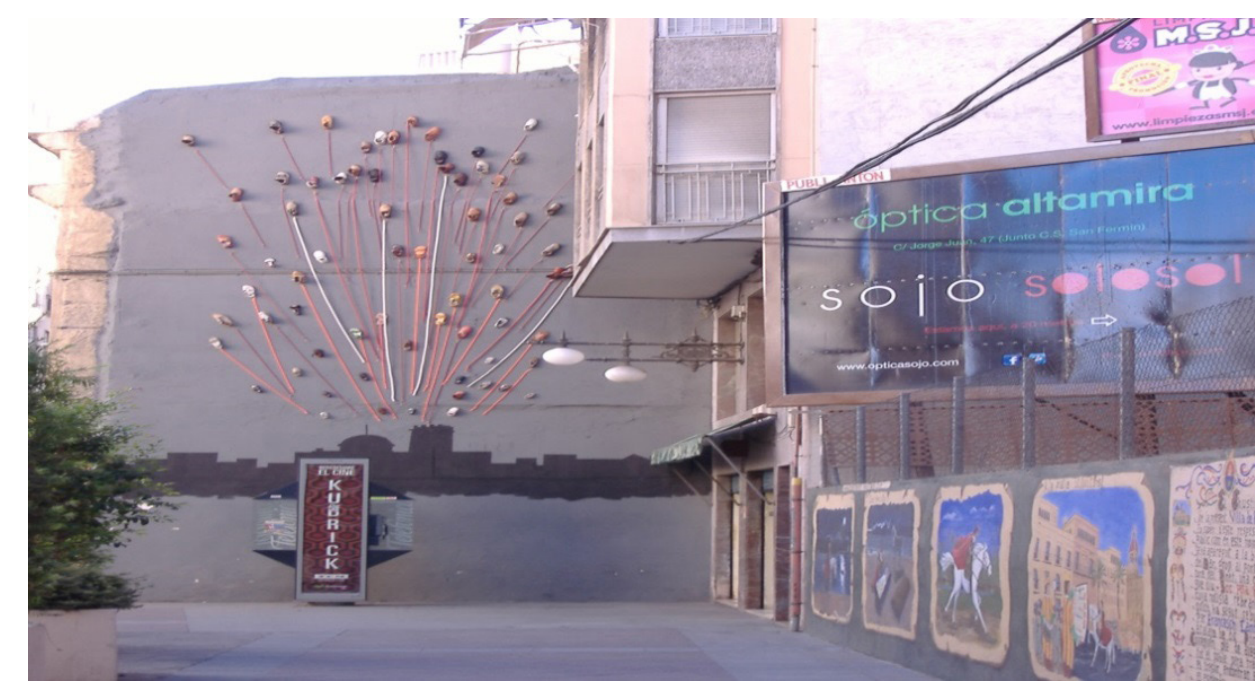

Ilustración 7: Mural que representa los brazos de la Palmera de la Virgen en la Nit de l’Albà con calzado.

Por otra parte, esta nueva legitimación permite también justificar prácticas de poder que tienden a reglamentar todo aquello que queda fuera de su control. Especialmente ilustrativo de estas contradicciones es el caso de la "Guerra de las carretillas". Definitivamente institucionalizado el Misteri, y privado así de su componente más festivo, la "Guerra de carretillas" se ha convertido en objetivo de la administración municipal. A esta celebración de carácter popular, tildada de salvaje y a la que la prensa reserva un espacio cada 14 de agosto para ofrecer el parte de heridos por quemaduras, se la ha intentado prohibir y, ante su imposibilidad, se la ha regulado (López, 2012). Frente a esto, se ha generado un discurso popular opuesto al oficial, con frases como "la Guerra de las carretillas es la fiesta de Elche y nos la quieren quitar",acompañado de prácticas de resistencia como continuar con las batallas de carretillas fuera de las áreas controladas.

Por último, siguiendo la estela de este proceso pero al margen del discurso y las políticas institucionales, el Museo de Pusol proporciona la evidencia de que en contextos turísticos prevalece la estrategia de "puesta en valor", ignorando o relegando prácticas que "dan valor" a la cultura (Nogués, 2006). Su inclusión en la lista UNESCO de Buenas Prácticas constituye una repatrimonialización paralela a la de Misteri y Palmeral, sin que eso haya supuesto ningún cambio en su estatus de elemento patrimonial honorable, aunque sin 
reconocérsele capacidad identitaria, y por ende, tampoco potencial turístico. Esta última cuestión queda reflejada en el Plan Estratégico de Turismo de Elche en el que el Museo de Pusol es incluido en un conjunto denominado "Museos de Elche" considerado como "recurso de potencial notable", categoría intermedia de las tres en que se clasifican los recursos turísticos municipales. En la categoría más importante aparece el único museo tratado individualmente, el Arqueológico y de Historia de Elche, apuesta emblemática del gobierno local, mientras que el Camp d'Elx, donde se encuentra el Museo de Pusol, queda relegado a la categoría más baja (Ayuntamiento de Elche, 2009: 9).

\section{CONCLUSIONES: LA REALIDAD DE TODAS LAS REALIDADES.}

Los símbolos son esenciales a la hora de representar lo inasible de la identidad. A su vez, la representación de la identidad, como elemento necesario para cualquier sociedad, en el caso ilicitanose forja a través de un diálogo muy marcado por las relaciones coloniales y la construcción del estado liberal: la Dama es vendida a una potencia colonial, los huertos de palmeras son barridos por el crecimiento urbano y el Misteri padecía constantes problemas económicos, a pesar de que la ciudad cada vez era más próspera. Sin embargo, la generalización de este tipo de procesos de modernización ha fomentado la patrimonialización de los símbolos identitarios ( $\mathrm{y}$ la atribución de funciones representativas de la identidad al patrimonio) como formas oficiales de distinción en un mercado global. La consecuencia directa de todo esto ha sido la conformación de una arena muy definida dedicada al Patrimonio y que cuenta con todas las características para ser analizada como un campo de entidad propia (Bourdieu, 1990: 119-126): instituciones mundiales, nacionales y locales, así como toda una normativa dirigida a la protección de elementos a los que se ha asignado la función de representar, caracterizar y garantizar la diversidad cultural a partir de valores como la Historia, la Tradición y/o la Memoria; además de, por supuesto, unos agentes sociales dispuestos a luchar por el capital simbólico que su control implica. Este nuevo campo del patrimonio cultural "no es sino uno más de los campos de significado o de los procedimientos mediante los que tratamos de suturar las fracturas y heridas del mundo contemporáneo [...] para asegurar la conectividad y continuidad inter-temporal" (Ariño, 2002: 17),y comprender mejor la relación entre poder y memoria que demanda el momento post-estatal (Nogués, 2014). Este uso del patrimonio muestra en el caso Elche esa relación entre patrimonio e identidad en un contexto de intensificación de lo local y lo global, y con ese deseo de proyección hacia el futuro que se esconde bajo el apelativo de Desarrollo.

La representación de la identidad local es un eje central en la lucha por el establecimiento de un discurso hegemónico. Así, desde la asunción de las palmeras como símbolo 
identificativo de Elche hasta el presente, los agentes locales que han intervenido en la forja de una representación identitaria actuaron en función de intereses hacia dentro y/o hacia afuera, con la intención de dar respuesta a procesos globalizadores de tinte económico que parecían diluir lo local, aunque curiosamente para tratar de evitarlo siguieran también unas pautas determinadas a escala mundial (Appadurai, 1990: 295). Es por esto que el proceso se llevó como algo opuesto a la modernización en su sentido económico que se percibía como enemiga de todo lo que el Patrimonio y cierta forma de identidad representaban.

Casi un siglo después de la venta de la Dama, una nuevo giro de los procesos globalizadores convierte al patrimonio, y a la forma de identidad representada a través de este, en recurso económico en un contexto en el que el turismo se consolida como la principal actividad económica mundial y las antiguas potencias se desindustrializan. Este desplazamiento ha contribuido a que el campo del patrimonio cultural estreche su vinculación con los componentes más econométricos de la realidad, como revela la patrimonialización para un mercado turístico que se acredita como la creación más perfecta del sistema capitalista. La sociedad ilicitana, inmersa como está en un contexto de desindustrialización, insiste en su urbanidad y continúa dando la espalda al medio rural. Impelida por las fuerzas globalizadoras a "poner en valor" su vieja tríada identitaria-patrimonial y encajarla en una estrategia de marca-ciudad, opta por dejar al margen las iniciativas que "dan valor" al patrimonio como el Museo de Pusol. Palmeral y Misteri, ahora repatrimonializados a nivel planetario (UNESCO) han sido consagrados a la noble tarea de atraer al turismo. Un nuevo cometido que les proporciona la posibilidad de ser reales de nuevo superando su existencia simbólica porque, como bien escribió Agustín García Calvo (2006: 29-30):

"Para ser reales, y mantenerse bien reales, es preciso mover el capital, amigos míos: pues el dinero es la realidad de las realidades; $y$ las cosas que no hayan logrado convertirse en dinero de uno u otro modo, ya pueden presumir de estar vivas y misteriosas, que habrán perdido la ocasión de realizarse realmente y quedarán condenadas a la existencia." 


\section{REFERENCIAS DOCUMENTALES}

Ayuntamiento de Elche (2006) "La población en Elche. Datos actualizados 2006" http:// www.economiaelche.com/docs/01.La_poblacion_en_Elche_2006.pdf [Consultado el 10 de agosto de 2014]

Ayuntamiento de Elche (2009) "Plan estratégico de turismo de Elche" http://servicios. laverdad.es/servicios/textos/plan-turismo-elche031209.pdf [Consultado el 10 de agosto de 2014]

Ayuntamiento de Elche (2013) "Población - Informes anuales estadísticos - Elche 2013" http://www.elche.es/media/tinyimages/file/Poblaci\%C3\%B3n2013.pdf [Consultado el 14 de agosto de 2014]

BOP (Boletín Oficial de la Provincia de Alicante), 7 de agosto de 2013, 149-1 http:// www.dip-alicante.es/bop2/pdftotal/2013/08/07-08-13-1.pdf\#page=2 [Consultado el 9 de noviembre de 2014]

López, Domingo (2012) "El Ayuntamiento suprime la zona acotada para la 'guerra de las carretillas' en las fiestas". Diario Información 2 de junio. http://www.diarioinformacion. com/elche/2012/06/02/ayuntamiento-suprime-zona-acotada-guerra-carretillasfiestas/1260389.html [Consultado el 9 de noviembre de 2014]

Maciá, Gaspar (2014) "Patrimonio en el ostracismo oficial". Periódico La Verdad, 16 de noviembre de 2014. http://www.laverdad.es/alicante/elche/201411/16/patrimonioostracismo-oficial-20141116003333-v.html._[Consultado el 7 de diciembre de 2014].

Mora Antón, Joaquina (2102) Informe sobre el comercio. Elche 2102. http://www.elche.es/ media/tinyimages/file/Informe Comercio Elx2012 ok.pdf [Consultado el 4 dde enero de 2014].

Turismo Elche 2013. Informes estadísticos anuales. Ayuntamiento de Elche.

http://www.elche.es/media/tinyimages/file/Turismo2013.pdf

UNESCO, (1992-2014) http://whc.UNESCO.org/en/about/ [Consultado el 3 de julio de 2014].

VistElche (2012) Plan de VisitElche http://es.slideshare.net/visitelche/plan-de-marketingvisitelchecom-2012 [Consultado el 4 de junio de 2014]. 


\section{REFERENCIAS BIBLIOGRÁFICAS}

Appadurai, Arjún (1990) "Disjuncture and difference in the global cultural economy". Theory, Culture and Society Vol.7, pp. 295-310.

Appadurai, Arjún (1996) Modernity at large: Cultural Dimensions of Globalization. University of Minnesota Press.

Ariño, Antonio (2010) "La patrimonialización de la cultura y sus paradojas posmodernas". En Davide Porporato (Coord.) Nuove pratiche di comunità. I patrimoni culturali etnoantropologici fra tradizione e complesità sociale. Turín: Omega Edizioni.

Bajtín, Mijaíl (1965) La cultura popular en la Edad Media y el Renacimiento: El contexto de François Rabelais. Madrid: Alianza Editorial.

Beck, Ulrich (1998) La sociedad del riesgo. Barcelona: Paidós.

Bourdieu, Pierre (1990) Sociología y cultura. México: Grijalbo.

Bourdieu, Pierre (2002) Campo de poder, campo intelectual. Buenos Aires: Montressor.

Brotons García, Baltasar (1995) El Camp d'Elx: història i tradició. Elche: Ayuntamiento de Elche.

Carmona Zubiri, Daniel y Nogués Pedregal, Antonio Miguel (2010) "Coping with two World Heritages. The two UNESCO declarations and local identity in Elche". Proceedings of the 2nd International Conference on Heritage and Sustainable Development. 22-26 June 2010. Amoeda, S. Liria and C. Pinheiro (eds.). Évora: Green Lines Institute for sustainable development. pp. 769-776

Castaño i García, Joan (1998) "Pere Ibarra i la defensa del patrimoni cultural", La Rella, pp. 47-64.

Castaño i García, Joan (2010) Les festes d'Elx. Alicante: Instituto Alicantino de Cultura Juan Gil-Albert.

Cutillas Orgilés, Ernesto (2006) "Elche y Elda-Petrer: La diferenciación entre dos núcleos industriales", Cuadernos de Geografía, 79, pp. 53-74.

Chadefaud, Michel (1987) Aux origines du tourisme dans les pays de l'Adour. Du mythe à l'espace. Un essai de géographie historique. Pau: Département de géographie et d'aménagement de l'Université de Pau et des pays de l'Adour, et Centre de recherche sur l'impact socio-spatial de l'aménagement (UA 911-CNRS).

Cremades García, Vicente José (2011) "Los órganos de gobierno del Misteri d’Elx: El Patronato rector y la Junta rectora”. Revista de la Facultad de Ciencias Sociales y Jurídicas de Elche, V. I, nº 7. Elche: UMH. pp. 52-75. 
Eisenstadt, Samuel Noah (1966) Modernization, Protest and Change. New Jersey: Englewood Cliffs, N. J., Prentice-Hall.

Frigolé, Joan (2014) "Retóricas de la autenticidad en el capitalismo avanzado". Endoxa, series filosóficas n³3, pp. 37-60. Madrid: UNED

Frondizi, Risieri (1958) ¿Qué son los valores? Introducción a la axiología. México: Fondo de Cultura Económica.

Fuster, Joan (1962) El País Valenciano. Barcelona: Ediciones Destino.

García Calvo, Agustín (2006) “¿Qué falta les hará a las pirámides de Egipto que vaya yo a verlas?”, Archipiélago 68, pp. 29-31. Madrid.

García García, José Luis (1988) "De la cultura como patrimonio al patrimonio cultural", Política y sociedad 27, pp. 9-20.

Gellner, Ernst (1994) Encounters with nationalism. Oxford. Spanishedition 1995: Encuentros con el nacionalismo. Madrid: Alianza.

Giddens, Anthony (1998) Conversations with Anthony Giddens: Making Sense of Modernity. Stanford: Standford University Press.

Gozálvez Pérez, Vicente (2006) "La ciudad”. En Miguel Ors (Dir.) Elche, una mirada histórica. Elche: Ayuntamiento de Elche. pp. 35-97

Gramsci, Antonio (1975) Quaderni del Carcere. I-IV. Torino: Einaudi.

Hernández-Ramírez, Javier (2009) "Hiperespecialización turística y desactivación del patrimonio. La gestión eclesiástica del Patio de los Naranjos de la Catedral de Sevilla”. En Patrimonio Cultural, Turismo y Religión. México DF: Ed. 1. pp. 13-33

Jaén i Urbán, Gaspar (1989) Guía de la arquitectura y el urbanismo de la ciudad de Elche. Elche: COACV, Generalitat Valenciana y Ayuntamiento de Elche.

Jeudy, Henri-Pierre (1990) Patrimoines en folie. Paris: Maison des Sciences de l'Homme. Larrosa Rocamora, José Antonio (2000) Atlas demográfico y social de la ciudad de Elche. Alicante: Publicaciones de la Universidad de Alicante.

Larrosa Rocamora, José Antonio (2003) "El palmeral de Elche: Patrimonio, gestión y turismo". Investigaciones geográficas no 30 . Alicante: Instituto Universitario de Geografía. pp. $77-96$

Llobregat Conesa, Enrique (1977) La Festad'Elx. Elche: Patronato Nacional del Misterio de Elche.

Martín Blanc, Genoveva (2006) "El lustro del cambio". En Miguel Ors Montenegro (dir.) Elche una mirada histórica. Elche: Ayuntamiento de Elche. pp. 472-491. 
Martínez Sanmartín, Luis Pablo (coord.) (2003) El palmeral de Elche: Un paisaje heredado de Al-Andalus. Elche: Ayuntamiento de Elche.

Miranda Encarnación, José Antonio (1991) Hacia un modelo industrial. Elche (18501930). Alicante: Instituto de Cultura Juan Gil-Albert.

Mora Antón, Joaquina (2006) "La Demografía”. En Miguel Ors Montenegro (dir.) Elche una mirada histórica. Elche: Ayuntamiento de Elche. pp.57-71

Moreno Sáez, Francisco (2006) "El movimiento obrero en la sociedad ilicitana (18901930)". En Miguel Ors Montenegro (dir.) Elche una mirada histórica. Elche: Ayuntamiento de Elche. pp. 271-299.

Nogués Pedregal, Antonio Miguel (2002) “Culture, deals and profitable meanings". En U. Kockel (ed.) Culture and economy: contemporary perspectives. Hampshire: Ashgate. pp. 147-163.

Nogués Pedregal, Antonio Miguel (2006) “"Dar valor" y "poner en valor". Dos estrategias para el desarrollo significativo del patrimonio en contextos turísticos". Actas del II Congreso Internacional de Patrimonio Cultural y Cooperación al Desarrollo. Valencia: Universidad Politécnica de Valencia. pp. 291-311

Nogués Pedregal, Antonio Miguel (2012) "When the Desirable and the Feasible Converge Through Tourism Space". En A.M. Nogués (ed.) Culture and Society in Tourism Contexts. Bingley: Emerald. pp. 57-90

Nogués Pedregal, Antonio Miguel (2014) “Tiempo y poder. La memoria ante el desarrollo". En Solér-García, C.; Caballero-Segarra, E. y Nogués-Pedregal, A.M. Conversatorio sobre interculturalidad y desarrollo. Elche: Cantera editorial. pp. 7-15

Olmos, Ricardo; Tortosa, Trinidad (1996) "El caso de la Dama de Elche: más que una divergencia”. Archivo Español de Arqueología 69, pp. 219-226.

Palazón Ferrando, Salvador (1989) “Cambios en la población de Elche entre 1970-1986. Un ejemplo de la crisis demográfica del País Valenciano". Investigaciones geográficas, 7 , pp. 191-204.

Paris, Pierre (1898) «Buste espagnol de style greco-asiatique trouvé a Elche», Paris: Monuments et Mémoires de la Fondation Piot, t. IV, pp.137-168.

Paris, Pierre (1907) «Promenades archéologiques en Espagne: Elche». Bulletin Hispanique, IX-4.11, pp.317-334.

Paris, Pierre (1910) Promenades archéologiques en Espagne. París: E. Leroux.

Prats. Llorens (1997) Antropología y Patrimonio. Barcelona: Arial.

Ramos Fernández, Rafael (1989) Historia de Elche. Alicante: Diario Información. 
Rodríguez Maciá, Manuel (2013) La Festa representació de la ciutat. Elche: Centro asociado de la UNED.

Ruíz Ballesteros, Esteban (2007) "Identidades en el desarrollo turístico". En Cuadernos docentes. Culturas, identidades y gestión turística. Universidad de Cuenca (Ecuador) Pág. 49-71.

San Miguel Del Hoyo, Begoña (2000) Elche: la fábrica dispersa: los trabajadores de la industria del calzado: cambios en las condiciones de vida y de trabajo. Alicante: Instituto de Cultura Juan Gil-Albert.

San Miguel Del Hoyo, Begoña (2002) "Braços per a treballar", La Rella, 15. Alicante: Universitatd'Alacant. pp. 71-86.

Sanz Alberola, Daniel (2006) "El régimen franquista en Elche: Política y sociedad”. En Miguel Ors Montenegro (dir.) Elche una mirada histórica. Elche: Ayuntamiento de Elche. pp. 354-381.

Swinburn, Henry (1779) Travels through Spain in the year 1775 and 1776 in which several monuments of Roman and Moorish architecture are illustrated by accurate drawings taken on the spot. Londres: Printedfor P. Elmsly.

Tortosa Rocamora, Trinidad (1996) "Algunos apuntes sobre los personajes y los textos en la historia de la dama de Elche", Revista de estudios ibéricos, nº 2, pp. 213-230.

Wallerstein, Inmanuel (2004) World-Systems Analysis: An Introduction. North Carolina: Duke University Press Durham. 